\title{
Publisher Correction: Polarized electron beams elastically scattered by atoms as a tool for testing fundamental predictions of quantum mechanics
}

\section{Maurizio Dapor ${ }^{1,2}$}

Correction to: Scientific Reports https://doi.org/10.1038/s41598-018-23660-4, published online 29 March 2018

The PDF version of this Article previously contained an incorrect link to the Supplementary Information.

Additionally, this Article contained an error in the legend of Figure 8 where,

"Solid lines: POLARe calculations (Cox and Bonham screening function ${ }^{15}$ with exchange)."

now reads:

"Solid lines: POLARe calculations (Cox and Bonham screening function ${ }^{15}$ without exchange)."

These errors have now been corrected in the HTML and PDF versions of this Article.

(i) Open Access This article is licensed under a Creative Commons Attribution 4.0 International License, which permits use, sharing, adaptation, distribution and reproduction in any medium or format, as long as you give appropriate credit to the original author(s) and the source, provide a link to the Creative Commons license, and indicate if changes were made. The images or other third party material in this article are included in the article's Creative Commons license, unless indicated otherwise in a credit line to the material. If material is not included in the article's Creative Commons license and your intended use is not permitted by statutory regulation or exceeds the permitted use, you will need to obtain permission directly from the copyright holder. To view a copy of this license, visit http://creativecommons.org/licenses/by/4.0/.

(c) The Author(s) 2018

\footnotetext{
${ }^{1}$ European Centre for Theoretical Studies in Nuclear Physics and Related Areas (ECT*-FBK), Trento, 38123, Italy. ${ }^{2}$ Trento Institute for Fundamental Physics and Applications (TIFPA-INFN), Trento, 38123, Italy. Correspondence and requests for materials should be addressed to M.D. (email: dapor@ectstar.eu)
} 